\title{
The management of carotid restenosis: a comprehensive review
}

\author{
Francesco Stilo ${ }^{1}$, Nunzio Montelione ${ }^{1}$, Rosalinda Calandrelli ${ }^{2}$, Marisa Distefano ${ }^{3}$, Francesco Spinelli ${ }^{1}$, \\ Vincenzo Di Lazzaro ${ }^{4}$, Fabio Pilato ${ }^{5}$
}

${ }^{1}$ Vascular Surgery Division, Campus Bio-Medico University of Rome, Rome, Italy; ${ }^{2}$ Fondazione Policlinico Universitario A. Gemelli - IRCCS, Roma, UOC Radiologia e Neuroradiologia, Dipartimento di Diagnostica per Immagini, Radioterapia Oncologica ed Ematologia, Rome, Italy; ${ }^{3}$ UOC Neurologia e UTN, Ospedale Belcolle, Strada Sammartinese 01100 Viterbo, Viterbo, Italy; ${ }^{4}$ Neurology, Neurophysiology, and Neurobiology Unit, Department of Medicine, Campus Bio-Medico University of Rome, Rome, Italy; ${ }^{5}$ Fondazione Policlinico Universitario A. Gemelli - IRCCS, Roma, UOC Neurologia, Dipartimento di Scienze Dell'invecchiamento, Neurologiche, Ortopediche e della Testa-collo, Roma, Italy

Contributions: (I) Conception and design: F Stilo, F Spinelli, V Di Lazzaro, F Pilato, N Montelione; (II) Administrative support: F Pilato, N Montelione; (III) Provision of study materials or patients: F Pilato, R Calandrelli, M Distefano, N Montelione; (IV) Collection and assembly of data: F Pilato, N Montelione, M Distefano, R Calandrelli; (V) Data analysis and interpretation: All authors; (VI) Manuscript writing: All authors; (VII) Final approval of manuscript: All authors.

Correspondence to: Nunzio Montelione, MD, PhD. Vascular Surgery Division, Campus Bio-Medico University of Rome, Via Alvaro del Portillo, Rome, Italy. Email: n.montelione@unicampus.it.

\begin{abstract}
Carotid artery stenosis (CS) is a major medical problem affecting approximately $10 \%$ of the general population 80 years or older and causes stroke in approximately $10 \%$ of all ischemic events. In patients with symptomatic, moderate-to-severe CS, carotid endarterectomy (CEA) and carotid angioplasty and stenting (CAS), has been used to lower the risk of stroke. In primary CS, CEA was found to be superior to best medical therapy (BMT) according to 3 large randomized controlled trials (RCT). Following CEA and CAS, restenosis remains an unsolved problem involving a large number of patients as the current treatment recommendations are not as clear as those for primary stenosis. Several studies have evaluated the risk of restenosis, reporting an incidence ranging from $5 \%$ to $22 \%$ after CEA and an in-stent restenosis (ISR) rate ranging from $2.7 \%$ to $33 \%$. Treatment and optimal management of this disease process, however, is a matter of ongoing debate, and, given the dearth of level 1evidence for the management of these conditions, the relevant guidelines lack clarity. Moreover, the incidence rates of stroke and complications in patients with carotid stenosis are derived from studies that did not use contemporary techniques and materials. Rapidly changing guidelines, updated techniques, and materials, and modern medical treatments make actual incidence rates barely comparable to previous ones. For these reasons, RCTs are critical for determining whether these patients should be treated with more aggressive treatments additional to BMT and identifying those patients indicated for surgical or endovascular treatments. This review summarizes the current evidence and controversies concerning the risks, causes, current treatment options, and prognoses in patients with restenosis after CEA or CAS.
\end{abstract}

Keywords: Ischemic stroke; carotid artery restenosis; endarterectomy; angioplasty; stenting

Submitted Jan 21, 2020. Accepted for publication Apr 27, 2020.

doi: $10.21037 /$ atm-20-963

View this article at: http://dx.doi.org/10.21037/atm-20-963

\section{Introduction}

Ischemic stroke is a significant cause of morbidity and mortality, and about $20 \%$ to $30 \%$ of all strokes are attributed to ipsilateral carotid plaque (1); therefore, carotid artery stenosis (CS) remains an important medical problem affecting approximately $10 \%$ of the general population and causing stroke in approximately $10 \%$ of all ischemic events (2). In patients with symptomatic, moderate-to-severe CS, carotid endarterectomy (CEA) and carotid angioplasty and stenting (CAS) has been implemented to lower the risk of 
stroke. Current guidelines concerning the time, techniques, and patient selection related to surgical and endovascular treatment remain controversial (3), but it is widely acknowledged that the overall morbidity and mortality rates associated with these procedures should be low, especially in asymptomatic patients $(4,5)$. Moreover, each procedure entails peculiar risks; for instance, CAS confers a higher risk of stroke, particularly in older patients, but has a lower risk of myocardial infarction (MI), cranial nerve injuries, and vessel hematoma in comparison to CEA (6-8); on the other hand, both treatments share a common risk of carotid artery restenosis. Several studies evaluated the risk of restenosis, reporting an incidence ranging from $5 \%$ to $22 \%$ after CEA, with in-stent restenosis (ISR) ranging from $2.7 \%$ to $33 \%$ (9-12), concluding that restenosis holds these patients in a state of significant stroke risk. The time-points for restenosis evaluation are also a matter of debate. Some studies evaluated vascular restenosis several times between 1 and 36 months after intervention (13). Meanwhile, CAS has been associated more often with residual or recurrent stenosis than CEA, even if it is driven by an excess rate of moderate stenosis, which might restrict its long-term efficacy for stroke prevention $(14,15)$. Some authors reported that at least moderate $(\geq 50 \%)$ restenosis occurred more frequently after CAS than after CEA and increased the risk for ipsilateral stroke (16). However, another study found significant symptomatic restenosis following CAS to be uncommon (17). Treatment and optimal management of this disease process thus remain a matter of ongoing debate and, due to level 1 evidence being scarce, the available guidelines do not yet provide sufficient clarity (5) in the management of these conditions.

This review summarizes the current evidence and controversies related to the risks, causes, current treatment options, and prognoses in patients with restenosis after CEA or CAS.

\section{Pathophysiological basis of restenosis}

Restenosis is commonly defined as a permanent narrowing of vessel diameter greater than $50 \%$ (as compared with a reference artery or complete occlusion) occurring more than 30 days after surgery $(18,19)$. Carotid restenosis both after CEA and CAS is a well-known threat and may represent a short- and long-term complication after the carotid intervention, exposing patients at risk to recurrent stroke and neurologic morbidity $(16,20)$. Restenosis is considered an abnormal wound-healing reaction, or a maladaptive response of the artery to trauma, induced during revascularization procedures. It is caused by the interaction of two main processes: neointimal hyperplasia and vascular remodeling. Neointimal hyperplasia is a process triggered by endothelial damage and results in the thickening of the tunica intima, while vascular remodeling is a change in the size of the involved vessel. Both processes are the result of several phenomena, including elastic recoil, extracellular matrix synthesis, and neo-adventitia formation at the injury site (21). Intimal proliferation, even if it is mainly caused by an endothelial response to manipulation, may be accelerated by external factors (e.g., diabetes mellitus) and inflammatory mediators such as C-reactive protein (CRP), plateletderived growth factor, and other agents (22-24). During therapeutic surgical or endovascular procedures, endothelial damage triggers neointimal hyperplasia by a cascade of inflammatory mediators, including free oxygen radicals, and mitogenic and chemotactic factors. Neointimal hyperplasia is supported by the contribution of several heterogeneous cell types, including smooth muscle cells, fibroblasts, circulating progenitor cells, adventitial myofibroblasts, and inflammatory cells (25), which precipitate the constrictive process that characterizes vascular narrowing.

Restenosis rate, the incidence of MI, stroke, and congestive heart failure may be influenced by genetic factors, but they appear more commonly in patients presenting concomitant atherosclerotic risk factors (26). These factors make understanding the underlying mechanisms responsible for this pathophysiological process and the identification of specific therapies for its prevention more difficult (27).

Carotid restenosis may have several causes determined primarily by the period in which restenosis develops. Early restenosis, defined as occurring within 3 years of intervention, has been mainly linked with myo-intimal hyperplasia; conversely, late restenosis, defined as occurring more than 3 years after the intervention, is thought to originate from recurrent carotid atherosclerosis $(28,29)$.

Several risk factors have been suggested as being responsible for restenosis and could be linked either with interventional techniques (surgical $v s$. endovascular) or with patient characteristics such as active smoking, diabetes mellitus, female gender, and stent type used in CAS $(30,31)$.

Atherosclerosis is a chronic process that is caused or at least accelerated, in part by some well-identified factors including hypertension, cigarette smoking, diabetes, and hyperlipidemia (32). The risks of the major thrombotic and thromboembolic complications of atherosclerosis appear 
to be related more to the stability of atheromatous plaques than to the extent of atherosclerotic disease (33).

Atherosclerosis-related carotid artery disease shares some common features with atherosclerosis-related coronary disease, including the potential risk of morbidity and mortality in particular (34). Although there may exist peculiar characteristics that indicate the presence of common pathophysiological mechanisms and risk factors for both conditions, these aspects may affect treatment and prognosis (35). While coronary disease develops earlier in life than carotid atherosclerosis (36), and the location in branching or curves and morphology of the plaques are different in the two arterial systems (33), both diseases are influenced by similar systemic factors. On the other hand, the degree of stenosis is not the only factor responsible for vascular events. Indeed, if a high degree of stenosis is highly predictive of stroke due to hypoperfusion and embolization, it has little ability to predict acute coronary syndrome in the coronary artery system, as this is determined mainly by local thrombosis from a ruptured or eroded plaque (35). These differences are even more pronounced in the restenosis process, and, despite numerous strategies being attempted to inhibit or reduce restenosis, the complex multifactorial nature of this pathophysiological process frequently leads to a failure of its prevention in patients (31).

\section{Restenosis after CEA and CAS}

The accepted indications for CEA balance the long-term benefit of stroke reduction with the risk of perioperative complications, requiring that the overall morbidity and mortality rates associated with CEA to be low $(<6 \%$ in symptomatic patients, $<3 \%$ in asymptomatic patients) enough to justify the intervention $(4,5)$. Complications following CEA are related to underlying cardiovascular disease and comorbidities and the surgical approach and technique used. The well-known postoperative complications of CEA include MI, perioperative stroke, postoperative bleeding, and the potential consequences of cervical hematoma, nerve injury, infection, with restenosis being a particularly harmful complication potentially requiring repeat carotid intervention (29).

Restenosis after CEA was reported in up to $20 \%$ of patients in early studies (37), but subsequent studies reported lower values (2.6\% to $10 \%$ at 5 years) $(9,38,39)$, and the risk of stroke recurrence after endarterectomy under best medical therapy (BMT) was reported to be $20 \%$ within 14 days and $37 \%$ in the first year (40).
Post CEA restenosis is typically caused by neointimal proliferation or thrombus formation. In the early stage after the intervention, commonly considered to the first 2 years after surgery, restenosis is usually attributed to the development of myo-intimal hyperplasia, while intermediate ( 2 to 5 years) and late ( $>5$ years) restenosis are deemed similar to primary atherosclerotic lesions (41).

Although surgical carotid revascularization is wellrecognized as the treatment of choice in symptomatic CS, during the later years, CAS has emerged as a useful and potentially less-invasive alternative to CEA for the treatment of extracranial carotid stenosis in high-risk patients, even though the actual level of evidence in favor of CAS is still low (42).

A study involving 507 patients enrolled in carotid ultrasound follow-up following CAS or CEA, reported a greater restenosis risk after CAS than after CEA, with a short-term rate of carotid restenosis of $\geq 50 \%$ and occlusion being about 2.5 times more common after CAS than after CEA. Both groups were in BMT, and no difference between the medical therapy of the groups was reported. Among patients with documented restenosis, the majority had recurrent restenosis, and only a few patients showed residual stenosis. On the other hand, the grading of restenosis was found to be mainly moderate, and the rates of recurrent cerebral ischemic events did not differ significantly between patients with or without restenosis (13).

The most important prospective, randomized, singlecenter study on restenosis revealed a higher incidence of relevant restenosis and neurologic symptoms after CAS than after CEA (43). Despite the small number of enrolled patients (87 patients) at 66 months of follow-up, 5 of the 32 CAS patients $(15.6 \%)$ presented with high-grade $(>70 \%)$ restenosis as an indication for secondary intervention or surgical stent removal, and 3 presented with neurologic symptoms; in contrast, no CEA patients required reintervention $(\mathrm{P}<0.05$ vs. CAS $)$.

Two randomized controlled trials comparing the results of CEA with CAS reported a significantly higher incidence of ISR after CAS $(15,16)$. The SPACE trial reported that the rate of restenosis $(\geq 70 \%)$ was $11.1 \%$ in the CAS group and $4.6 \%$ in the CEA group $(\mathrm{P}=0.0007)$ with only two neurological symptoms in recurrent stenosis being reported after CAS (15). Meanwhile, the ICSS trial reported that the cumulative 5 -year risk of restenosis $(\geq 50 \%)$ was $40.7 \%$ in the CAS group and $29.6 \%$ in the CEA group $(\mathrm{P}<0.0001)$, and increased the risk for ipsilateral stroke in the overall population (16). 
Finally, for patients undergoing CAS, inflammation seems to have a central role in atherosclerotic disease progression, and some serum biomarkers have been linked with ISR. For instance, one study found that CRP level at 48 hours, exemplary of the post-intervention acutephase response, was significantly associated with 6-month restenosis (44). Tables 1 and 2 summarize the restenosis cases recorded in the principal studies of CEA and CAS.

\section{Risk factors for restenosis after CEA and CAS}

Several studies have described the risk factors associated with restenosis after CEA $(29,85,86)$. However, even if the results from single-center studies that lack uniformity in inclusion criteria, diagnostic tools, and follow-up schemes, cannot be considered conclusive, some important findings have been obtained. Expectedly, associations between restenosis and vascular risk factors, including hyperlipidemia (87), hypertension (88), smoking $(89,90)$, and metabolic syndrome (91), have been observed.

Two non-modifiable risk factors, including a family history of stroke and age $<65$ years, have been reported to predispose patients to disease progression and recurrence (90). Further studies showed that homocysteine (92), and severe renal insufficiency (93) significantly correlated with carotid restenosis. Patients with end-stage renal disease can develop endothelial dysfunction through several mechanisms, including elevated low-density lipoprotein, decreased adiponectin levels, and decreased clearance of proinflammatory and oxidative substances (94). Inflammation also plays a role in early carotid restenosis after CEA, as demonstrated by the elevated risk of restenosis associated with a rise in the high-sensitivity CRP level before CEA and increased fibrinogen $48 \mathrm{~h}$ after surgery $(95,96)$.

Characteristics of target lesions may also influence the rate of restenosis. The high content of calcium in plaque is a predictor of restenosis at 6 months both after CEA and after CAS (97).

Finally, some researchers studied the risk of restenosis related to the surgical approach. They found that, in the early postoperative surgical period, the technical defects predominate. For instance, a residual plaque at the distal endpoint and a step in the common carotid artery (CCA) take part in the pathogenesis of restenosis (28). Moreover, the female gender has been described as a risk factor for restenosis after CEA $(29,98)$. This association could be attributed to anatomic factors, as women have smaller artery diameters and are thus more prone to develop restenosis (99), but sex hormones could also play a role in the progression of the atheromatous plaque.

In contrast to CEA, no difference exists between men and women in terms of ISR after CAS (100). The CREST trial, however, did report that female gender, diabetes, and dyslipidemia were independent predictors of restenosis after CAS. In this trial, smoking was associated with an increased likelihood of restenosis only after CEA (19). Some authors reported that patch closure of CEA was associated with a statistically significant lower risk of restenosis compared with primary closure (94). On the other hand, researchers in the CAVATAS trial identified smoking as an independent risk factor for restenosis both after CEA and after CAS (14), while Khan et al. reported that advancing age was a predictor of restenosis after CAS (101).

Similarly to CEA, chronic renal failure (94), metabolic syndrome (91), and hypertension (102) were associated with increased rates of restenosis. Zapata-Arriaza et al. (102) speculated that high blood pressure could trigger endothelial dysfunction and promote inflammation and smooth muscle cell proliferation at the site of stent placement. Moreover, these authors reported vasoreactivity (IVR) to be an ultrasonographic marker of endothelial dysfunction in small-vessel compensation mechanisms and an independent risk predictor of restenosis. Recently, a history of cardiovascular disease was reported as a predictor for $>50 \%$ restenosis (20).

Concerning clinical status, symptomatic status at presentation has also been found to be associated with a significantly lower risk of restenosis after carotid revascularization. However, this could have been a confounded result as the symptomatic patients might have received more medical therapy compared with those without presenting symptoms (94).

Characteristics of the target lesion may also influence the rate of restenosis. Plaques longer than $20 \mathrm{~mm}$ (103) and calcifications (104) were significantly related to restenosis. Anatomical, technical, and hemodynamic features, such as multiple stents, a lack of stent coverage in the CCA, residual stenosis after CAS, and contralateral carotid stenosis (12), also potentially play a role in the restenosis process (101-103).

Furthermore, the CREST trial reported an inverse proportion between increasing age and the outcomes of CAS, thus implicating age as a negative effect on the outcome of CAS (105).

Concerning restenosis after CAS, 3 forms of ISR have been described. "In-stent" restenosis is the more common form and likely arises from neo-intimal hyperplasia caused 
Table 1 Studies evaluating patients with restenosis after CEA

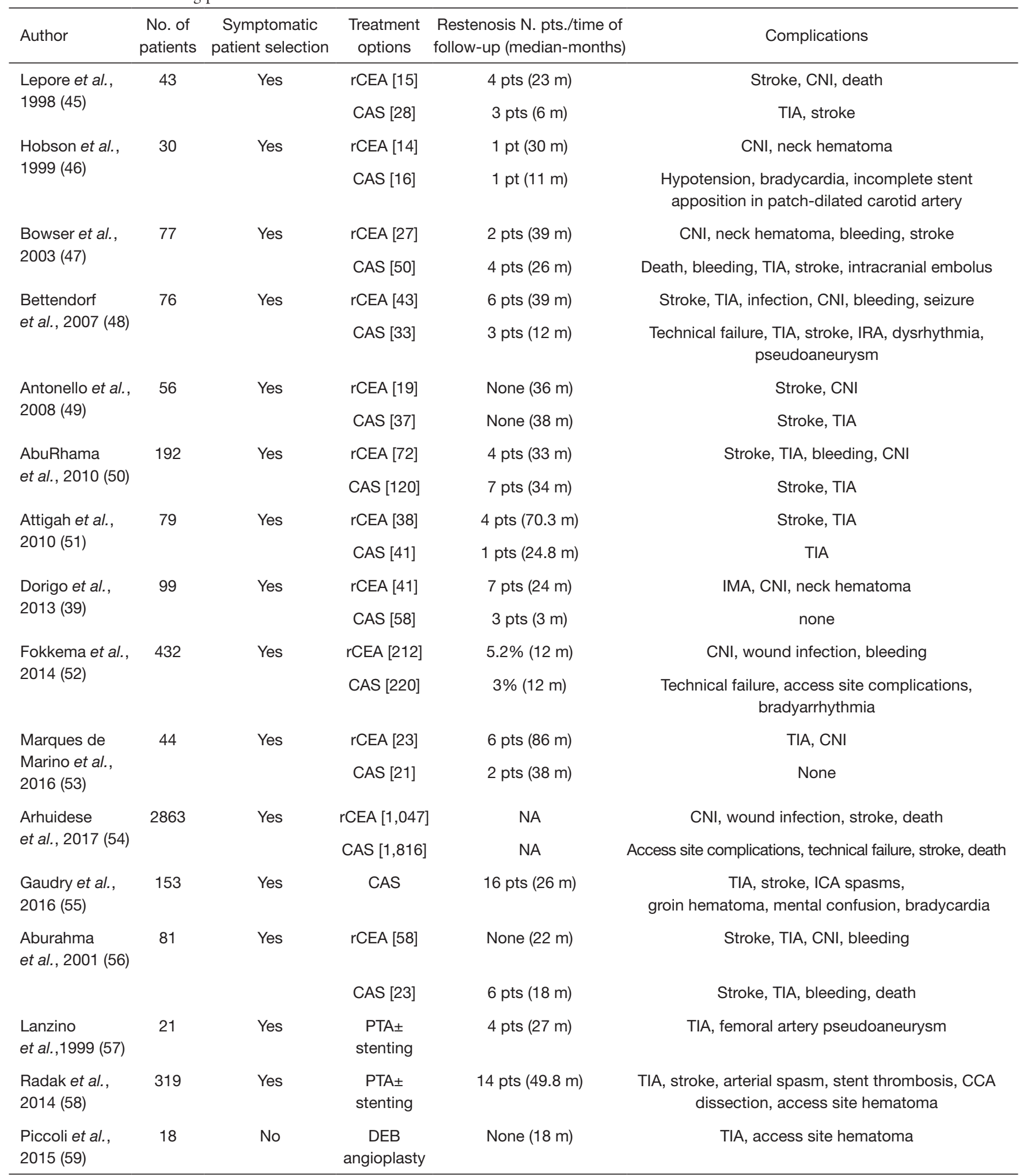

BA, balloon-angioplasty; CAS, carotid angioplasty and stenting; CB-PTA, cutting balloon percutaneous transluminal angioplasty; CEA, carotid endarterectomy; CNI, cranial nerve injury; DEB, drug-eluting balloon angioplasty; PTA, percutaneous transluminal angioplasty. 
Table 2 Studies evaluating patients with restenosis after CAS

\begin{tabular}{|c|c|c|c|c|c|}
\hline Study & $\begin{array}{l}\text { No. of } \\
\text { pts. }\end{array}$ & $\begin{array}{l}\text { Symptomatic patient } \\
\text { selection }\end{array}$ & Treatment options & $\begin{array}{l}\text { Restenosis No. pts./time of } \\
\text { follow-up (median-months) }\end{array}$ & Complications \\
\hline $\begin{array}{l}\text { Gonzalez et al., } \\
2011(60)\end{array}$ & 3 & Yes & CEA & None (12.5 m) & None \\
\hline $\begin{array}{l}\text { Chakhtoura et al., } \\
2001 \text { (61) }\end{array}$ & 4 & No & PTA or PTA + stenting & None (18 m) & None \\
\hline Lal et al., 2003 (63) & 4 & No & PTA or PTA + stenting & 2 pts (18.8 m) & None \\
\hline $\begin{array}{l}\text { Setacci et al., } \\
2005 \text { (64) }\end{array}$ & 3 & Yes & CEA or surgical embolectomy & None & None \\
\hline $\begin{array}{l}\text { Setacci et al., } \\
2005(65)\end{array}$ & 15 & Yes & PTA, PTA + stenting, CB-PTA & None (NA) & None \\
\hline $\begin{array}{l}\text { Zhou et al., } \\
2006 \text { (67) }\end{array}$ & 7 & Yes & PTA, PTA + stenting, CB-PTA & 2 pts $(9 \mathrm{~m})$ & None \\
\hline $\begin{array}{l}\text { Vale et al., } \\
1997 \text { (68) }\end{array}$ & 1 & No & CEA & None $(6 \mathrm{w})$ & None \\
\hline $\begin{array}{l}\text { de Borst et al., } \\
2003 \text { (69) }\end{array}$ & 4 & Yes & CEA & None $(13 \mathrm{~m})$ & $\begin{array}{c}\text { Worsening of } \\
\text { neurological status in } \\
\text { symptomatic patients }\end{array}$ \\
\hline $\begin{array}{l}\text { Reedy et al., } \\
2000 \text { (70) }\end{array}$ & 2 & No & CEA & NA & None \\
\hline $\begin{array}{l}\text { Koebbe et al., } \\
2005 \text { (73) }\end{array}$ & 22 & Yes & PTA + stenting & 1 pt (36 m) & $\begin{array}{l}\text { Groin/retroperitoneal } \\
\text { hematoma }\end{array}$ \\
\hline $\begin{array}{l}\text { Gandini et al., } \\
2014(74)\end{array}$ & 9 & Yes & DEB angioplasty & 3 pts (36.6 m) & Tia \\
\hline \multirow{2}{*}{$\begin{array}{l}\text { Montorsi et al., } \\
2012(75)\end{array}$} & & & DEB angioplasty (7 pts) & None (13.7 m) & Stroke \\
\hline & 10 & No & Cutting balloons (3 pts) & None (1 year) & None \\
\hline $\begin{array}{l}\text { Pohlmann et al., } \\
2018 \text { (76) }\end{array}$ & 9 & Yes & DEB angioplasty & $1 \mathrm{pt}(\mathrm{NA})$ & None \\
\hline $\begin{array}{l}\text { Tekieli et al., } \\
2012 \text { (77) }\end{array}$ & 7 & No & $\begin{array}{l}\text { balloon-mounted drug-eluting stent } \\
\text { (DES) }\end{array}$ & 2 pts (17 m) & Tia \\
\hline $\begin{array}{l}\text { Donas et al., } \\
2011 \text { (78) }\end{array}$ & 16 & Yes & CEA, BA, stenting & 5 pts (NA) & $\mathrm{Na}$ \\
\hline
\end{tabular}

Table 2 (continued) 
Table 2 (continued)

\begin{tabular}{|c|c|c|c|c|c|}
\hline Study & $\begin{array}{l}\text { No. of } \\
\text { pts. }\end{array}$ & $\begin{array}{l}\text { Symptomatic patient } \\
\text { selection }\end{array}$ & Treatment options & $\begin{array}{l}\text { Restenosis No. pts./time of } \\
\text { follow-up (median-months) }\end{array}$ & Complications \\
\hline $\begin{array}{l}\text { Heck et al., } \\
2009 \text { (79) }\end{array}$ & 6 & No & CB-PTA & 1 pt (20 m) & None \\
\hline $\begin{array}{l}\text { Reimers et al., } \\
2006 \text { (80) }\end{array}$ & 31 & Yes & CB-PTA & $1 \mathrm{pt}(17 \mathrm{~m})$ & None \\
\hline $\begin{array}{l}\text { Reichmann et al., } \\
2011 \text { (82) }\end{array}$ & 15 & Yes & CEA & None (21 m) & $\begin{array}{l}\text { Stroke, neck } \\
\text { hematoma }\end{array}$ \\
\hline $\begin{array}{l}\text { Yu et al., } \\
2017 \text { (83) }\end{array}$ & 10 & Yes & CEA & 1 pt (25 m) & $\begin{array}{l}\text { CNI, cerebral } \\
\text { hyperperfusion, } \\
\text { dissection }\end{array}$ \\
\hline
\end{tabular}

BA, balloon-angioplasty; CAS, carotid angioplasty and stenting; CB-PTA, cutting balloon percutaneous transluminal angioplasty; CEA, carotid endarterectomy; CNI, cranial nerve injury; DEB, drug-eluting balloon angioplasty; PTA, percutaneous transluminal angioplasty.

by symmetrical or asymmetrical narrowing of the lumen within the stent after an initial positive result. "End-ofstent" restenosis is like recurrent stenosis after carotid patch thromboendarterectomy and has been ascribed to local factors or technical errors. The less frequent type is "tandem" restenosis and may be the most benign type in terms of treatment durability (17).

Gaudry et al. analyzed the anatomical factors related to the onset of ISR and found that lesions located on the distal carotid artery and a CCA diameter $<7.5 \mathrm{~mm}$ were also significantly associated with ISR (55).

\section{Radiological evaluation of carotid restenosis}

In primary CS, the degree of the stenosis is a well-known risk and surrogate index for carotid intervention (55,106-108). However, recent improvements in imaging techniques like ultrasonography, computed tomography angiography (CTA), magnetic resonance angiography (MRA), and positron emission tomography (PET)/CT allow multidimensional plaque composition to assess the risk and vulnerability, beyond the degree of stenosis alone (109). The cost-effectiveness of a routine ultrasound screening of restenosis after CEA has been questioned (110), but, due to a potential risk of early restenosis, it has been recommended after CAS procedures (111). Carotid restenosis of $50 \%$ to $69 \%$ is commonly diagnosed on planimetry according to the North American Symptomatic Carotid Endarterectomy Trial (NASCET) method, which involves comparing the lumen diameter of the carotid artery (at the narrowest point of stenosis) to the lumen diameter of the normal internal carotid artery (ICA) distal to the stenosis. In contrast, carotid restenosis of $\geq 70 \%$ or occlusion has been diagnosed when it is present on either planimetry or velocity parameters (13). ICA peak systolic velocities $>210 \mathrm{~cm} / \mathrm{s}$ (112) and $>300 \mathrm{~cm} / \mathrm{s}(113,114)$ were used to define carotid restenosis $>70 \%$, in post CEA and CAS, respectively.

Restenosis may be a poor result of inadequate revascularization and can be classified as residual stenosis; otherwise, if it occurs after successful revascularization, it may lead to recurrent stenosis. Recurrent stenosis is defined as the absence of residual stenosis at 1 month, with later development of $>50 \%$ stenosis or occlusion (13).

The usefulness of several diagnostic tools has been reported in patients with CS at elevated risk of future stroke. These tools include detection of microembolic signals (MES) by transcranial doppler ultrasound (115), analysis of unstable carotid plaque or progression in the severity of CS by carotid doppler ultrasound, plaque hemorrhage by magnetic resonance imaging (MRI) or silent embolic infarcts on cerebral computed tomography (CT), or MRI $(116,117)$. Due to the lack of specific RCTs, these diagnostic techniques could be useful tools in selecting patients with restenosis at high-risk for stroke. 
Follow-up vascular imaging after CAS or CEA should be performed to detect restenosis caused by thrombus formation or neointimal hyperplasia. If carotid artery restenosis is suspected, duplex sonography, CTA or MRA, or selective digital subtraction angiography may supply information about stenosis severity.

Biplanar or rotational digital subtraction angiography (DSA) is the gold standard of diagnosing carotid stenosis because it allows an accurate diagnosis both in the case of vessel tortuosity and stenosis in non-orthogonal planes. However, this technique is invasive and requires the use of nephrotoxic contrast agents and significant external beam radiation exposure $(118,119)$. The advent of other noninvasive imaging studies, such as duplex ultrasonography, MRA, and CTA has replaced and, in some instances (e.g., the assessment of plaque morphology), has surpassed conventional angiography in the follow-up for carotid artery disease.

Although duplex ultrasonography is often strongly dependent on the examiner's skills, it has been shown to assess recurrent stenosis after CEA accurately. However, recent studies have shown that the current velocity criteria used to assess stenosis after the stented artery yield a high falsepositive rate (120). Stent implantation in the carotid artery alters the expansible properties of the artery to resemble a rigid tube and thus reduces the compliance of the stented vessel, resulting in artificially increased velocities due to a compliance mismatch between the stent and artery (121); consequently, some authors have proposed revision of the velocity criteria following stented artery (122).

Unlike Doppler ultrasonography, both CTA and MRA, with the use of high-resolution acquisitions, supply more detailed information regarding neo-intimal surface and plaque morphology. Some studies demonstrated that sensitivity and specificity of blood-pool contrastenhanced MRA exceed that of multi-detector CT angiography (MDCTA) both in post-stenting/post endarterectomy restenosis and in the assessment of plaque morphology (123).

Although the stent material causing stent artifacts influences restenosis assessment, both CTA and MRA allow for the adequate evaluation of in-stent lumen and plaque characterization. Stent imaging with CT is afflicted by the artificial narrowing of the in-stent lumen and beam-hardening artifacts, which may hamper restenosis assessment (124). Moreover, stenosis evaluation with multi-planar reformation is exact only when the stent is in parallel and oblique orientations relative to the table axis $(118,125)$. Also, metallic artifacts are more pronounced in stents with tantalum markers compared with nitinol stents without markers.

On the other hand, MRI of vascular stents is limited by susceptibility and radiofrequency (RF)-shielding artifacts related to the metallic composition of the stent. In one study, metallic artifacts were found to be mostly related to the stent orientation with $\mathrm{B} 0$, while the orientation of the read-out gradient had little influence. In general, stents made of nitinol or tantalum alloy induce fewer artifacts than cobalt and stainless-steel stents (118).

MR and CT are useful techniques for stenosis measurements, and they are similar for both modalities with slight overestimation (less than 10\%) of ISR. Moreover, magnetic resonance diffusion-weighted imaging (DWI) may give information for detecting procedure-related cerebral infarction, and has been recommended to all patients within 7 days after CAS and CEA (126).

The evolution of CTA and MRA technology promises an even greater ability to characterize plaque composition and morphology. Currently, MRI is the gold standard in carotid plaque imaging by its high resolution and high sensitivity for identifying intraplaque hemorrhage (IPH), ulceration, lipid-rich necrotic core (LRNC), and inflammation (127). However, the usefulness of MRI is limited by its time constraints. CTA also allows high-resolution imaging and can accurately detect ulceration and calcification but cannot reliably differentiate LRNC from IPH $(109,128)$.

The main limitations to MDCTA include beamhardening artifacts arising from densely calcified plaques, the need for iodinated contrast, and radiation exposure (121). Alternatively, MRA is noninvasive and does not require any radiation or iodinated contrast administration. However, the limitations of MRA include restrictions on use for patients with claustrophobia, pacemakers, implantable defibrillators, and obesity. Also, the MRA contrast agent, gadolinium, has been reported to be associated with renal and extra-renal toxicity. Patients with renal insufficiency or those already on dialysis appear to be at particular risk for nephrogenic systemic fibrosis (129-131).

\section{Indications for reintervention after restenosis}

If the results and recommendations regarding indications and treatments in primary CS can be considered contentious, then there is even more uncertainty concerning carotid restenosis after CEA or CAS; moreover, no treatment guidelines exist for treating ISR, and physicians must rely on the extent of stenosis, clinical symptoms, and 
vascular compensation to make clinical decisions (132).

In patients with CS, BMT is reported to be effective for the management of the majority of patients, but in some patients, medical therapy cannot prevent stroke, and a more aggressive treatment could be required (40). In a recent study involving asymptomatic patients with CS in primary prevention, BMT was evaluated alone or in combination with CAS or CEA. The study was prematurely stopped after the randomization of 513 patients due to a low recruitment rate, and there was insufficient power to determine whether CEA or CAS was superior to BMT alone in the primary prevention of ischemic stroke in patients with asymptomatic carotid stenosis up to 1 year after treatment. However, a statistically non-significant increase in the rate of restenosis occurred in the CAS group (CEA 2.0\% vs. CAS 5.6\%), although stroke rates were not increased (133).

The choice for treatment is even more difficult for patients in whom either CEA or CAS is complicated by restenosis. As reported from different clinical experiences, a secondary intervention in these high-risk patients may be hazardous (134). Redo CEA is often challenging due to the presence of scar tissue in the field, and thus CAS has appeared as an alternative treatment for post-CEA restenosis. Moreover, in recent years, the number of CAS procedures has increased even though the standard of care for treating post-CEA stenosis has not been established. As high rates of ISR may be observed in patients with hostile neck condition $(134,135)$, it is important to identify specific groups of patients with restenosis in which BMT alone is not enough to reduce stroke risk.

A systematic review identified 50 studies reporting on post-CEA or CAS restenosis and found that the criteria for treatment of carotid restenosis were not sufficiently rigorous and that there was significant ambiguity surrounding the indications for intervention (11). Patients were generally treated when the degree of restenosis exceeded $80 \%$, but only $23 \%(444 / 1,926)$ of symptomatic patients had documented ipsilateral symptoms; also, patients were not evaluated for other sources of emboli, and the remaining $45.3 \%$ of patients were asymptomatic. Most patients (68\%) underwent redo CEA, while CAS was performed in $32 \%$ of the patients. Even if acceptable outcomes after reoperation following primary CEA have been reported (136), recent studies have highlighted the usefulness of CAS in the surgical hostile neck (such as after irradiation) or high cervical lesion restenosis (137).

Even though no RCTs have evaluated whether symptomatic restenosis should be treated medically or by redo surgery, the latest European Society for Vascular Surgery (ESVS) guidelines (4) suggests adopting the same treatment criteria that are used to select symptomatic patients with primary atherosclerotic stenosis. Accordingly, treating symptomatic restenosis (50-99\%) by CEA or CAS within 14 days of symptoms is recommended. Nevertheless, asymptomatic restenosis is still a highly controversial subject. Despite an intuitive belief that most asymptomatic restenosis is benign, the same guidelines (4) suggest that reintervention may be considered in post-CEA 70-99\% asymptomatic restenosis, following a multidisciplinary team review. Conversely, it is recommended that asymptomatic restenosis $>70 \%$ after CAS should be treated medically, as the risk of stroke is minimal. This because about $97 \%$ of all late ipsilateral strokes after CAS occurs in patients without restenosis $>70 \%$. By contrast, a severe asymptomatic restenosis $>70 \%$ after CEA, does appear to be associated with a significantly higher risk of late ipsilateral stroke.

When a decision has been made to undertake revascularisation in patients with restenosis, the choice of redo CEA or CAS should be based on multidisciplinary team review, local surgeon/interventionist experience, and patient choice (4).

\section{CEA vs. CAS for recurrent carotid stenosis}

Restenosis remains an unsolved problem following CEA and CAS, and current treatment recommendations are not as clear as those for primary stenosis; moreover, consistent data from randomized clinical trials are lacking to evaluate better the relative risk of carotid restenosis in patients treated with CAS as compared with those treated with CEA (13). The inconsistent evidence for recurrent stenosis after earlier carotid treatment with ongoing BMT presents a difficult choice concerning reoperation. This because repeated CEA significantly increases the incidence of complications, as suggested by retrospective studies, even if some conflicting conclusions about good outcomes have also been reported $(136,138)$. An additional concern is that RCTs have not been performed for re-operative CEA in patients with restenosis, but supposed benefits due to surgery are indirect evidence from trials of primary intervention at initial stenosis. Moreover, early recurrent carotid lesions are typically smooth and linked with intimal hyperplasia (41) with a minimal risk of thromboembolism.

According to guidelines, CAS was showed as the treatment of choice in post-CEA restenosis when reintervention is deemed appropriate to avoid complications 
related to repeated CEA $(139,140)$. However, a single-center study (141) reported similar results with both techniques even if patients in the CAS group had better outcomes in terms of secondary restenosis; furthermore, all patients were free from secondary restenosis at 4 years in the CAS group compared to $72.5 \%$ in the redo CEA group. Also, a meta-analysis including 13 studies with 4,163 patients with post CEA restenosis demonstrated comparable results with similar risks of periprocedural stroke, transient ischemic attack (TIA), myocardial infarction (MI), and death in CAS and CEA groups, with lower risks for new restenosis and cranial nerve injury in patients treated with CAS (85). Thus, the results consistently suggest that CAS is more beneficial than repeated CEA in the setting of restenosis; indeed, the guidelines of the American Heart Association (AHA) and the Society of Vascular Surgery suggest CAS treatment of post-CEA stenosis.

A systematic review involving 4,399 patients with carotid restenosis who had undergone repeated carotid intervention (surgery or stenting) following CEA reported no significant difference in the perioperative (30 days) rates for mortality, stroke, or TIA between CEA and CAS for carotid restenosis. However, the risk of early and late complications was low for both procedures. An increase in the incidence of cranial nerve injury after repeated CEA compared with that after undergoing CAS was reported, even though it was transient and usually resolved within 3 months. On the other hand, another study found that the risk of recurrent stenosis was greater in CAS patients than in patients who underwent repeated CEA (142).

Other authors have also reported a similar primary endpoint of stroke and death for CAS and CEA $(2.7 \%$ and $2.3 \%$ respectively) in patients treated for restenosis (479 CEA and 653 CAS) (143), while still, other research has described re-operative CEA outcomes, but these series were limited, or the group samples were barely comparable (144-146).

Some patients that require a particular approach are those with ISR after CAS, as no treatment guideline exists for this condition, and physicians need to make decisions using clinical judgment (132). Angioplasty with or without restenting is commonly used in these patients. Angioplasty is inferior to angioplasty with stenting in de-novo carotid stenosis, but it was reported as a satisfactory treatment in some case series in ISR even though its durability was short and the restenosis risk was high $(61,63,65)$. On the other hand, because CAS is used as an alternative treatment in the high-risk population, CEA is often not a treatment option for ISR but may become a reasonable choice for patients without increased surgical risk (82). However, a doublecenter study reported satisfactory results for patients treated by carotid bypass (CB) for symptomatic high-grade ISR after CAS. In this series performed on 13 patients, CB (either with great saphenous vein or polytetrafluoroethylene grafts), a $100 \%$ patency rate at a mean follow-up of $41.2 \pm 18.2$ months with a minimal risk of transient cranial nerve damage $(7.7 \%)$ was reported (84).

According to a previously published experience with CB after CEA failure (139), the authors decided to submit patients to a more radical surgical solution by performing a complete exclusion of the diseased carotid wall after stent removal (84).

A few additional studies have directly compared CAS and surgical treatment for ISR (147), with the authors reporting no significant difference in 1-year outcomes between the two groups.

Moreover, the current incidence rates of stroke and complications in patients with carotid stenosis are derived from dated epidemiological studies. Due to rapidly changing guidelines and updated BMTs, the actual incidence rates are hardly comparable to those of the past. This discrepancy makes conducting updated RCTs mandatory for determining whether these patients should be treated and which treatment should be performed in a specific scenario.

\section{Conclusions}

The selection of the patients by anatomic factors related to neck or vascularization or some clinical variables such as risk factors and or comorbidities could help develop risk stratification tools that indicate the most efficacious secondary intervention for carotid revascularization. Moreover, due to the number of treatments available such as BMT, CEA, angioplasty, angioplasty with stenting, and the possibility to redo each of these procedures more times, the selection of patients and procedure presents an even more significant challenge.

Because RCTs and level 1 evidence are not available for restenosis treatment, the identification of patients at an increased risk of restenosis is essential for optimizing the selection of patients and procedures for the most durable intervention, for developing the best therapy management, and for establishing a careful strategy for post-procedural clinical and imaging surveillance.

\section{Acknowledgments}

Funding: None. 


\section{Footnote}

Provenance and Peer Review: This article was commissioned by the Guest Editor (Dr. Kosmas I. Paraskevas) for the series "Carotid Artery Stenosis and Stroke: Prevention and Treatment Part I" published in Annals of Translational Medicine. The article was sent for external peer review organized by the Guest Editor and the editorial office.

Conflicts of Interest: All authors have completed the ICMJE uniform disclosure form (available at http://dx.doi. org/10.21037/atm-20-963). The series "Carotid Artery Stenosis and Stroke: Prevention and Treatment Part I" was commissioned by the editorial office without any funding or sponsorship. The authors have no other conflicts of interest to declare.

Ethical Statement: The authors are accountable for all aspects of the work in ensuring that questions related to the accuracy or integrity of any part of the work are appropriately investigated and resolved.

Open Access Statement: This is an Open Access article distributed in accordance with the Creative Commons Attribution-NonCommercial-NoDerivs 4.0 International License (CC BY-NC-ND 4.0), which permits the noncommercial replication and distribution of the article with the strict proviso that no changes or edits are made and the original work is properly cited (including links to both the formal publication through the relevant DOI and the license). See: https://creativecommons.org/licenses/by-nc-nd/4.0/.

\section{References}

1. Go AS, Mozaffarian D, Roger VL, et al. Heart disease and stroke statistics--2014 update: a report from the American Heart Association. Circulation 2014;129:e28-e292.

2. Abbott AL, Paraskevas KI, Kakkos SK, et al. Systematic review of guidelines for the management of asymptomatic and symptomatic carotid stenosis. Stroke 2015;46:3288-301.

3. Moresoli P, Habib B, Reynier P, et al. Carotid Stenting Versus Endarterectomy for Asymptomatic Carotid Artery Stenosis: A Systematic Review and Meta-Analysis. Stroke. 2017;48:2150-7.

4. Naylor AR, Ricco JB, de Borst GJ, et al. European Society of Vascular Surgery guidelines on the management of atherosclerotic carotid and vertebral artery disease. Eur J
Vasc Endovasc Surg 2018;55:3-81.

5. Brott TG, Halperin JL, Abbara S, et al. ASA/ACCF/ AHA/AANN/AANS/ACR/ASNR/CNS/SAIP/SCAI/ SIR/SNIS/SVM/SVS guideline on the management of patients with extracranial carotid and vertebral artery disease. A report of the American College of Cardiology Foundation/American Heart Association Task Force on Practice Guidelines, and the American Stroke Association, American Association of Neuroscience Nurses, American Association of Neurological Surgeons, American College of Radiology, American Society of Neuroradiology, Congress of Neurological Surgeons, Society of Atherosclerosis Imaging and Prevention, Society for Cardiovascular Angiography and Interventions, Society of Interventional Radiology, Society of NeuroInterventional Surgery, Society for Vascular Medicine, and Society for Vascular Surgery. Circulation 2011;124:54-130.

6. Mas JL, Chatellier G, Beyssen B, et al. Endarterectomy versus Stenting in Patients with Symptomatic Severe Carotid Stenosis. N Engl J Med 2006;355:1660-71.

7. Featherstone RL, Dobson J, Ederle J, et al. Carotid artery stenting compared with endarterectomy in patients with symptomatic carotid stenosis (International Carotid Stenting Study): a randomised controlled trial with costeffectiveness analysis. Health Technol Assess 2016;20:1-94.

8. SPACE Collaborative Group, Ringleb PA, Allenberg J, et al. 30 day results from the SPACE trial of stent-protected angioplasty versus carotid endarterectomy in symptomatic patients: a randomised non-inferiority trial. Lancet 2006;368:1239-47.

9. LaMuraglia GM, Stoner MC, Brewster DC, et al. Determinants of carotid endarterectomy anatomic durability: Effects of serum lipids and lipid-lowering drugs. J Vasc Surg 2005;41:762-8.

10. Sadideen H, Taylor PR, Padayachee TS. Restenosis after carotid endarterectomy. Int J Clin Pract 2006;60:1625-30.

11. Bekelis K, Moses Z, Missios S, et al. Indications for treatment of recurrent carotid stenosis. Br J Surg 2013;100:440-7.

12. Wasser K, Schnaudigel S, Wohlfahrt J, et al. Clinical impact and predictors of carotid artery in-stent restenosis. J Neurol 2012;259:1896-902.

13. Arquizan C, Trinquart L, Touboul PJ, et al. Restenosis Is More Frequent After Carotid Stenting Than After Endarterectomy. Stroke 2011;42:1015-20.

14. Bonati LH, Ederle J, McCabe DJH, et al. Long-term risk of carotid restenosis in patients randomly assigned to endovascular treatment or endarterectomy in the Carotid 
and Vertebral Artery Transluminal Angioplasty Study (CAVATAS): long-term follow-up of a randomised trial. Lancet Neurol 2009;8:908-17.

15. Eckstein H-H, Ringleb P, Allenberg J-R, et al. Results of the Stent-Protected Angioplasty versus Carotid Endarterectomy (SPACE) study to treat symptomatic stenoses at 2 years: a multinational, prospective, randomised trial. Lancet Neurol 2008;7:893-902.

16. Bonati LH, Gregson J, Dobson J, et al. Restenosis and risk of stroke after stenting or endarterectomy for symptomatic carotid stenosis in the International Carotid Stenting Study (ICSS): secondary analysis of a randomised trial. Lancet Neurol 2018;17:587-96.

17. Ierardi AM, Angileri SA, Brambillasca PM, et al. In-stent restenosis associated with dual-layer Roadsaver carotid artery stent: a retrospective single-center study. Radiol Med 2019;124:704-9.

18. Lespérance J, Bourassa MG, Schwartz L, et al. Definition and measurement of restenosis after successful coronary angioplasty: implications for clinical trials. Am Heart J 1993;125:1394-408.

19. Lal BK, Beach KW, Roubin GS, et al. Restenosis after carotid artery stenting and endarterectomy: a secondary analysis of CREST, a randomised controlled trial. Lancet Neurol 2012;11:755-63.

20. Daou B, Chalouhi N, Starke RM, et al. Predictors of restenosis after carotid artery stenting in 241 cases. J Neurointerv Surg 2016;8:677-9.

21. Goel SA, Guo LW, Liu B, et al. Mechanisms of postintervention arterial remodelling. Cardiovasc Res 2012;96:363-71.

22. Moore WS, Kempczinski RF, Nelson JJ, et al. Recurrent carotid stenosis: results of the asymptomatic carotid atherosclerosis study. Stroke 1998;29:2018-25.

23. Willfort-Ehringer A, Ahmadi R, Gessl A, et al. Neointimal proliferation within carotid stents is more pronounced in diabetic patients with initial poor glycaemic state. Diabetologia 2004;47:400-6.

24. Simonetti G, Gandini R, Versaci F, et al. Carotid artery stenting: findings based on 8 years' experience. Radiol Med 2009;114:95-110.

25. Hosono M, Ueda M, Suehiro S, et al. Neointimal formation at the sites of anastomosis of the internal thoracic artery grafts after coronary artery bypass grafting in human subjects: an immunohistochemical analysis. J Thorac Cardiovasc Surg 2000;120:319-28.

26. Lingman M, Albertsson P, Herlitz J, et al. The impact of hypertension and diabetes on outcome in patients undergoing percutaneous coronary intervention. Am J Med 2011;124:265-75.

27. Forte A, Rinaldi B, Berrino L, et al. Novel potential targets for prevention of arterial restenosis: insights from the pre-clinical research. Clin Sci 2014;127:615-34.

28. Hunter GC. The clinical and pathologic spectrum of recurrent carotid stenosis. Am J Surg 1997;174:583-8.

29. Trisal V, Paulson T, Hans SS, et al. Carotid artery restenosis: An ongoing disease process. Am Surg 2002;68:275-9.

30. Callow AD. Recurrent Stenosis After Carotid Endarterectomy. Arch Surg 1982;117:1082-5.

31. Texakalidis P, Giannopoulos S, Kokkinidis DG, et al. Effect of Open- vs Closed-Cell Stent Design on Periprocedural Outcomes and Restenosis After Carotid Artery Stenting: A Systematic Review and Comprehensive Meta-analysis. J Endovasc Ther 2018;25:523-33.

32. Schulz UGR, Rothwell PM. Differences in Vascular Risk Factors Between Etiological Subtypes of Ischemic Stroke. Stroke 2003;34:2050-9.

33. Rothwell PM, Villagra R, Gibson R, et al. Evidence of a chronic systemic cause of instability of atherosclerotic plaques. Lancet 2000;355:19-24.

34. Roger VL, Go AS, Lloyd-Jones DM, et al. Heart Disease and Stroke Statistics-2011 Update. Circulation 2011;123:e18-e209.

35. Jashari F, Ibrahimi P, Nicoll R, et al. Coronary and carotid atherosclerosis: similarities and differences. Atherosclerosis 2013;227:193-200.

36. Solberg LA, McGarry PA, Moossy J, et al. Distribution of cerebral atherosclerosis by geographic location, race, and sex. Lab Invest 1968;18:604-12.

37. Zierler RE, Bandyk DF, Thiele BL, et al. Carotid artery stenosis following endarterectomy. Arch Surg 1982;117:1408-15.

38. Goodney PP, Nolan BW, Eldrup-Jorgensen J, et al. Vascular Study Group of Northern New England. Restenosis after carotid endarterectomy in a multicenter regional registry. J Vasc Surg 2010;52:897-904, 905.e1-2; discussion 904-5.

39. Dorigo W, Pulli R, Fargion A, et al. Comparison of open and endovascular treatments of post-carotid endarterectomy restenosis. Eur J Vasc Endovasc Surg 2013;45:437-42.

40. Shahidi S, Owen-Falkenberg A, Gottschalksen B, et al. Risk of early recurrent stroke in symptomatic carotid stenosis after best medical therapy and before endarterectomy. Int J Stroke 2016;11:41-51. 
41. Domanin M, Gallo D, Vergara C, et al. Prediction of Long Term Restenosis Risk After Surgery in the Carotid Bifurcation by Hemodynamic and Geometric Analysis. Ann Biomed Eng 2019;47:1129-40.

42. de Donato G, Setacci F, Pasqui E, et al. Early carotid artery stenting after onset neurologic symptoms. Semin Vasc Surg 2018;31:15-20.

43. Steinbauer MG, Pfister K, Greindl M, et al. Alert for increased long-term follow-up after carotid artery stenting: results of a prospective, randomized, single-center trial of carotid artery stenting vs carotid endarterectomy. J Vasc Surg 2008;48:93-8

44. Schillinger M, Exner M, Mlekusch W, et al. Acute-Phase Response after Stent Implantation in the Carotid Artery: Association with 6-month In-Stent Restenosis. Radiology 2003;227:516-21.

45. Lepore MR, Jordan WD, Fisher WS, et al. Treatment of Recurrent Carotid Stenosis: Angioplasty with Stenting versus Reoperative Carotid Surgery. Vascular Surgery 1998;32:523-30.

46. Hobson RW, Goldstein JE, Jamil Z, et al. Carotid restenosis: operative and endovascular management. J Vasc Surg 1999;29:228-35; discussion 235-8.

47. Bowser AN, Bandyk DF, Evans A, et al. Outcome of carotid stent-assisted angioplasty versus open surgical repair of recurrent carotid stenosis. J Vasc Surg 2003;38:432-8.

48. Bettendorf MJ, Mansour MA, Davis AT, et al. Carotid angioplasty and stenting versus redo endarterectomy for recurrent stenosis. Am J Surg 2007;193:356-9.

49. Antonello M, Deriu GP, Frigatti P, et al. Does the type of carotid artery closure influence the management of recurrent carotid artery stenosis? Results of a 6-year prospective comparative study. Surgery 2008;143:51-7.

50. AbuRahma AF, Abu-Halimah S, Hass SM, et al. Carotid artery stenting outcomes are equivalent to carotid endarterectomy outcomes for patients with post-carotid endarterectomy stenosis. J Vasc Surg 2010;52:1180-7.

51. Attigah N, Külkens S, Deyle C, et al. Redo Surgery or Carotid Stenting for Restenosis after Carotid Endarterectomy: Results of Two Different Treatment Strategies. Ann Vasc Surg 2010;24:190-5.

52. Fokkema M, Borst GJ de, Nolan BW, et al. Carotid stenting versus endarterectomy in patients undergoing reintervention after prior carotid endarterectomy. J Vasc Surg 2014;59:8-15.e1.

53. Marques de Marino P, Martinez Lopez I, Hernandez Mateo MM, et al. Open Versus Endovascular Treatment for Patients with Post-Carotid Endarterectomy Restenosis: Early and Long-term Results. Ann Vasc Surg 2016;36:159-65.

54. Arhuidese I, Obeid T, Nejim B, et al. Stenting versus endarterectomy after prior ipsilateral carotid endarterectomy. J Vasc Surg 2017;65:1-11.

55. Gaudry M, Bartoli J-M, Bal L, et al. Anatomical and Technical Factors Influence the Rate of In-Stent Restenosis following Carotid Artery Stenting for the Treatment of Post-Carotid Endarterectomy Stenosis. PLoS One 2016;11:e0161716.

56. Aburahma AF, Bates MC, Stone PA, et al. Comparative study of operative treatment and percutaneous transluminal angioplasty/stenting for recurrent carotid disease. J Vasc Surg 2001;34:831-8.

57. Lanzino G, Mericle RA, Lopes DK, et al. Percutaneous transluminal angioplasty and stent placement for recurrent carotid artery stenosis. J Neurosurg 1999;90:688-94.

58. Radak D, Tanaskovic S, Sagic D, et al. Carotid angioplasty and stenting is safe and effective for treatment of recurrent stenosis after eversion endarterectomy. J Vasc Surg. 2014;60:645-51.

59. Piccoli G, Biondi-Zoccai G, Gavrilovic V, et al. DrugCoated Balloon Dilation Before Carotid Artery Stenting of Post-Carotid Endarterectomy Restenosis. J Endovasc Ther 2015;22:212-6.

60. Gonzalez A, Drummond M, McCord S, et al. Carotid endarterectomy for treatment of in-stent restenosis. J Vasc Surg 2011;54:1167-9.

61. Chakhtoura EY, Hobson RW, Goldstein J, et al. In-stent restenosis after carotid angioplasty-stenting: incidence and management. J Vasc Surg 2001;33:220-5; discussion 225-6.

62. Willfort-Ehringer A, Ahmadi R, Gschwandtner ME, et al. Single-center experience with carotid stent restenosis. J Endovasc Ther 2002;9:299-307.

63. Lal BK, Hobson RW, Goldstein J, et al. In-stent recurrent stenosis after carotid artery stenting: life table analysis and clinical relevance. J Vasc Surg 2003;38:1162-8; discussion 1169 .

64. Setacci C, de Donato G, Setacci F, et al. Surgical management of acute carotid thrombosis after carotid stenting: a report of three cases. J Vasc Surg 2005;42:993-6.

65. Setacci C, de Donato G, Setacci F, et al. In-stent restenosis after carotid angioplasty and stenting: a challenge for the vascular surgeon. Eur J Vasc Endovasc Surg 2005;29:601-7.

66. Levy EI, Hanel RA, Lau T, et al. Frequency and 
management of recurrent stenosis after carotid artery stent implantation. J Neurosurg 2005;102:29-37.

67. Zhou W, Lin PH, Bush RL, et al. Management of in-sent restenosis after carotid artery stenting in high-risk patients. J Vasc Surg 2006;43:305-12.

68. Vale FL, Fisher WS, Jordan WD, et al. Carotid endarterectomy performed after progressive carotid stenosis following angioplasty and stent placement. Case report. J Neurosurg 1997;87:940-3.

69. de Borst GJ, Ackerstaff RGA, Mauser HW, et al. Operative management of carotid artery in-stent restenosis: first experiences and duplex follow-up. Eur J Vasc Endovasc Surg 2003;26:137-40.

70. Reedy FM, Colonna M, Genovese V, et al. Successful surgical treatment of two patients with restenosis after previous stenting of the carotid artery. Eur J Vasc Endovasc Surg 2000;20:99-101.

71. Jost D, Unmuth SJ, Meissner H, et al. Surgical treatment of carotid in-stent-restenosis: novel strategy and current management. Thorac Cardiovasc Surg 2012;60:517-24.

72. Chung J, Valentine W, Sharath SE, et al. Percutaneous intervention for carotid in-stent restenosis does not improve outcomes compared with nonoperative management. J Vasc Surg 2016;64:1286-1294.e1.

73. Koebbe CJ, Liebman K, Veznedaroglu E, et al. Carotid artery angioplasty and stent placement for recurrent stenosis. Neurosurgical Focus 2005;18:e7.

74. Gandini R, Del Giudice C, Da Ros V, et al. Long-term results of drug-eluting balloon angioplasty for treatment of refractory recurrent carotid in-stent restenosis. J Endovasc Ther 2014;21:671-7.

75. Montorsi P, Galli S, Ravagnani PM, et al. Drug-Eluting Balloon for Treatment of In-Stent Restenosis After Carotid Artery Stenting: Preliminary Report. J Endovasc Ther 2012;19:734-42.

76. Pohlmann C, Höltje J, Zeile M, et al. Recurrent stenosis following carotid artery stenting treated with a drugeluting balloon: a single-center retrospective analysis. Neuroradiology 2018;60:81-7.

77. Tekieli L, Pieniazek P, Musialek P, et al. Zotarolimuseluting stent for the treatment of recurrent, severe carotid artery in-stent stenosis in the TARGET-CAS population. J Endovasc Ther 2012;19:316-24.

78. Donas KP, Eisenack M, Torsello G. Balloon Angioplasty for In-Stent Stenosis After Carotid Artery Stenting Is Associated With an Increase in Repeat Interventions. J Endovasc Ther 2011;18:720-5.

79. Heck D. Results of cutting balloon angioplasty for carotid artery in-stent restenosis in six patients: description of the technique, long-term outcomes, and review of the literature. J Neurointerv Surg 2009;1:48-50.

80. Reimers B, Tübler T, de Donato G, et al. Endovascular Treatment of In-Stent Restenosis after Carotid Artery Stenting: Immediate and Midterm Results. J Endovasc Ther 2006;13:429-35.

81. Marcucci G, Accrocca F, Giordano A, et al. Results of surgical repair of carotid in-stent restenosis. J Cardiovasc Surg (Torino) 2012;53:707-14.

82. Reichmann BL, van Laanen JH, de Vries JPP, et al. Carotid endarterectomy for treatment of in-stent restenosis after carotid angioplasty and stenting. J Vasc Surg 2011;54:87-92.

83. Yu LB, Yan W, Zhang Q, et al. Carotid endarterectomy for treatment of carotid in-stent restenosis: long-term followup results and surgery experiences from one single centre. Stroke Vasc Neurol 2017;2:140-6.

84. Stilo F, Sirignano P, Montelione N, et al. Bypass for symptomatic in-stent carotid restenosis. Int J Cardiol 2017;249:392-95.

85. Texakalidis P, Giannopoulos S, Jonnalagadda AK, et al. Carotid Artery Endarterectomy versus Carotid Artery Stenting for Restenosis After Carotid Artery Endarterectomy: A Systematic Review and Meta-Analysis. World Neurosurg 2018;115:421-429.e1.

86. Ouriel K, Green RM. Clinical and technical factors influencing recurrent carotid stenosis and occlusion after endarterectomy. J Vasc Surg 1987;5:702-6.

87. Rapp JH, Qvarfordt P, Krupski WC, et al. Hypercholesterolemia and early restenosis after carotid endarterectomy. Surgery 1987;101:277-82.

88. Avramovic JR, Fletcher JP. The incidence of recurrent carotid stenosis after carotid endarterectomy and its relationship to neurological events. J Cardiovasc Surg (Torino) 1992;33:54-8.

89. Cuming R, Worrell P, Woolcock NE, et al. The influence of smoking and lipids on restenosis after carotid endarterectomy. Eur J Vasc Surg 1993;7:572-6.

90. Ladowski JS, Shinabery LM, Peterson D, et al. Factors contributing to recurrent carotid disease following carotid endarterectomy. Am J Surg 1997;174:118-20.

91. Casana R, Malloggi C, Tolva VS, et al. Does metabolic syndrome influence short and long term durability of carotid endarterectomy and stenting? Diabetes Metab Res Rev 2019;35:e3084.

92. Bakoyiannis C, Karaolanis G, Moris D, et al. Homocysteine as a risk factor of restenosis after carotid endarterectomy. Int Angiol 2015;34:166-71. 
93. Avgerinos ED, Chaer RA, Naddaf A, et al. Primary closure after carotid endarterectomy is not inferior to other closure techniques. J Vasc Surg 2016;64:678-683.e1.

94. Texakalidis P, Tzoumas A, Giannopoulos S, et al. Risk Factors for Restenosis After Carotid Revascularization: A Meta-Analysis of Hazard Ratios. World Neurosurg 2019;125:414-24.

95. Tanaskovic S, Radak D, Aleksic N, et al. Scoring system to predict early carotid restenosis after eversion endarterectomy by analysis of inflammatory markers. J Vasc Surg 2018;68:118-27.

96. Széplaki G, Varga L, Laki J, et al. Elevated complement C3 is associated with early restenosis after eversion carotid endarterectomy. Thromb Haemost 2006;96:529-34.

97. Katano H, Mase M, Nishikawa Y, et al. Surgical treatment for carotid stenoses with highly calcified plaques. J Stroke Cerebrovasc Dis 2014;23:148-54.

98. Zbornikova V, Elfstrom J, Lassvik C, et al. Restenosis and occlusion after carotid surgery assessed by duplex scanning and digital subtraction angiography. Stroke 1986;17:1137-42.

99. Krejza J, Arkuszewski M, Kasner SE, et al. Carotid artery diameter in men and women and the relation to body and neck size. Stroke 2006;37:1103-5.

100. Skelly CL, Gallagher K, Fairman RM, et al. Risk factors for restenosis after carotid artery angioplasty and stenting. J Vasc Surg 2006;44:1010-5.

101. Khan MA, Liu MW, Chio FL, et al. Predictors of restenosis after successful carotid artery stenting. Am J Cardiol 2003;92:895-7.

102.Zapata-Arriaza E, Moniche F, González A, et al. Predictors of Restenosis Following Carotid Angioplasty and Stenting. Stroke 2016;47:2144-7.

103. Shankar JJS, Zhang J, dos Santos M, et al. Factors affecting long-term restenosis after carotid stenting for carotid atherosclerotic disease. Neuroradiology 2012;54:1347-53.

104. Ronchey S, Praquin B, Orrico M, et al. Outcomes of 1000 Carotid Wallstent Implantations: Single-Center Experience. J Endovasc Ther 2016;23:267-74.

105. Brott TG, Hobson RW, Howard G, et al. Stenting versus endarterectomy for treatment of carotid-artery stenosis. N Engl J Med 2010;363:11-23.

106. Endarterectomy for asymptomatic carotid artery stenosis. Executive Committee for the Asymptomatic Carotid Atherosclerosis Study. JAMA 1995;273:1421-8.

107. Halliday A, Mansfield A, Marro J, et al. Prevention of disabling and fatal strokes by successful carotid endarterectomy in patients without recent neurological symptoms: randomised controlled trial. Lancet 2004;363:1491-502.

108. Hobson RW, Weiss DG, Fields WS, et al. Efficacy of carotid endarterectomy for asymptomatic carotid stenosis. The Veterans Affairs Cooperative Study Group. N Engl J Med 1993;328:221-7.

109. Brinjikji W, Huston J, Rabinstein AA, et al. Contemporary carotid imaging: from degree of stenosis to plaque vulnerability. J Neurosurg 2016;124:27-42.

110. Post PN, Kievit J, van Baalen JM, et al. Routine duplex surveillance does not improve the outcome after carotid endarterectomy: a decision and cost utility analysis. Stroke 2002;33:749-55.

111. Gröschel K, Riecker A, Schulz JB, et al. Systematic Review of Early Recurrent Stenosis After Carotid Angioplasty and Stenting. Stroke 2005;36:367-73.

112. Carpenter JP, Lexa FJ, Davis JT. Determination of duplex Doppler ultrasound criteria appropriate to the North American Symptomatic Carotid Endarterectomy Trial. Stroke 1996;27:695-9.

113. Setacci C, Chisci E, Setacci F, et al. Grading carotid intrastent restenosis: a 6-year follow-up study. Stroke 2008;39:1189-96.

114.Lal BK, Hobson RW, Tofighi B, et al. Duplex ultrasound velocity criteria for the stented carotid artery. J Vasc Surg 2008;47:63-73.

115. Best LMJ, Webb AC, Gurusamy KS, et al. Transcranial Doppler Ultrasound Detection of Microemboli as a Predictor of Cerebral Events in Patients with Symptomatic and Asymptomatic Carotid Disease: A Systematic Review and Meta-Analysis. Eur J Vasc Endovasc Surg 2016;52:565-80.

116. Paraskevas KI, Spence JD, Veith FJ, et al. Identifying which patients with asymptomatic carotid stenosis could benefit from intervention. Stroke 2014;45:3720-4.

117.Paraskevas KI, Veith FJ, Spence JD. How to identify which patients with asymptomatic carotid stenosis could benefit from endarterectomy or stenting. Stroke Vasc Neurol 2018;3:92-100.

118.Létourneau-Guillon L, Soulez G, Beaudoin G, et al. CT and MR imaging of nitinol stents with radiopaque distal markers. J Vasc Interv Radiol 2004;15:615-24.

119. Maldonado TS. What are current preprocedure imaging requirements for carotid artery stenting and carotid endarterectomy: have magnetic resonance angiography and computed tomographic angiography made a difference? Semin Vasc Surg 2007;20:205-15.

120. Chi Y-W, White CJ, Woods TC, et al. Ultrasound velocity 
criteria for carotid in-stent restenosis. Catheter Cardiovasc Interv 2007;69:349-54.

121. Goldman CK, Morshedi-Meibodi A, White CJ, et al. Surveillance imaging for carotid in-stent restenosis. Catheter Cardiovasc Interv 2006;67:302-8.

122. Bosch FT, Hendrikse J, Davagnanam I, et al. Optimal cutoff criteria for duplex ultrasound compared with computed tomography angiography for the diagnosis of restenosis in stented carotid arteries in the international carotid stenting study. Eur Stroke J 2017;2:37-45.

123. Anzidei M, Napoli A, Geiger D, et al. Preliminary experience with MRA in evaluating the degree of carotid stenosis and plaque morphology using high-resolution sequences after gadofosveset trisodium (Vasovist) administration: comparison with CTA and DSA. Radiol Med 2010;115:634-47.

124.Lettau M, Kotter E, Bendszus M, et al. Carotid artery stents on CT angiography: in vitro comparison of different stent designs and sizes using 16-, 64- and 320-row CT scanners. J Neuroradiol 2014;41:259-68.

125. Wise SW, Hopper KD, Ten Have T, et al. Measuring carotid artery stenosis using CT angiography: the dilemma of artifactual lumen eccentricity. AJR Am J Roentgenol 1998;170:919-23.

126. Yan D, Tang X, Shi Z, et al. Perioperative and Followup Results of Carotid Artery Stenting and Carotid Endarterectomy in Patients with Carotid Near-Occlusion. Ann Vasc Surg 2019;59:21-7.

127. Gupta A, Baradaran H, Schweitzer AD, et al. Carotid plaque MRI and stroke risk: a systematic review and metaanalysis. Stroke 2013;44:3071-7.

128. Misaki K, Uchiyama N, Mohri M, et al. Prediction of carotid artery in-stent restenosis by quantitative assessment of vulnerable plaque using computed tomography. J Neuroradiol 2016;43:18-24.

129. Nikolsky E, Mehran R. Understanding the consequences of contrast-induced nephropathy. Rev Cardiovasc Med 2003;4:S10-S18.

130.Perazella MA, Rodby RA. Gadolinium-induced nephrogenic systemic fibrosis in patients with kidney disease. Am J Med 2007;120:561-2.

131. Sadowski EA, Bennett LK, Chan MR, et al. Nephrogenic systemic fibrosis: risk factors and incidence estimation. Radiology 2007;243:148-57.

132. Wangqin R, Krafft PR, Piper K, et al. Management of De Novo Carotid Stenosis and Postintervention RestenosisCarotid Endarterectomy Versus Carotid Artery Stenting-a Review of Literature. Transl Stroke Res 2019;10:460-74.
133. Reiff T, Eckstein HH, Mansmann U, et al. Angioplasty in asymptomatic carotid artery stenosis vs. endarterectomy compared to best medical treatment: One-year interim results of SPACE-2. Int J Stroke 2019:1747493019833017. [Epub ahead of print].

134. Spinelli F, Martelli E, Stilo F, et al. Carotid bypass: a safe and durable solution for recurrent carotid stenosis, Ann Vasc Surg 2014;28:1329-34.

135.Moon K, Albuquerque FC, Levitt MR, et al. The myth of restenosis after carotid angioplasty and stenting. J Neurointerv Surg 2016;8:1006-10.

136. Archie JP. Reoperations for carotid artery stenosis: Role of primary and secondary reconstructions. J Vasc Surg 2001;33:495-503.

137.Arya S, Pipinos II, Garg N, et al. Carotid Endarterectomy is Superior to Carotid Angioplasty and Stenting for Perioperative and Long-Term Results. Vasc Endovascular Surg 2011;45:490-8.

138. Coscas R, Rhissassi B, Gruet-Coquet N, et al. Open surgery remains a valid option for the treatment of recurrent carotid stenosis. J Vasc Surg 2010;51:1124-32.

139. Furie KL, Kasner SE, Adams RJ, et al. Guidelines for the prevention of stroke in patients with stroke or transient ischemic attack: a guideline for healthcare professionals from the American Heart Association/American Stroke Association. Stroke 2011;42:227-76.

140.Hobson RW 2nd, Mackey WC, Ascher E, et al. Management of atherosclerotic carotid artery disease: clinical practice guidelines of the Society for Vascular Surgery. J Vasc Surg 2008;48:480-6.

141.Dorigo W, Fargion A, Giacomelli E, et al. A propensity matched comparison for open and endovascular treatment of post-carotid endarterectomy restenosis. Eur J Vasc Endovasc Surg 2018;55:153-61.

142.Tu J, Wang S, Huo Z, et al. Repeated carotid endarterectomy versus carotid artery stenting for patients with carotid restenosis after carotid endarterectomy: Systematic review and meta-analysis. Surgery 2015;157:1166-73.

143. Fokkema M, Vrijenhoek JEP, Den Ruijter HM, et al. Stenting versus endarterectomy for restenosis following prior ipsilateral carotid endarterectomy: an individual patient data meta-analysis. Ann Surg 2015;261:598-604.

144.Mansour MA, Kang SS, Baker WH, et al. Carotid endarterectomy for recurrent stenosis. J Vasc Surg 1997;25:877-83.

145. Kresowik TF, Bratzler DW, Kresowik RA, et al. Multistate improvement in process and outcomes of carotid 
endarterectomy. J Vasc Surg 2004;39:372-80.

146. Stoner MC, Cambria RP, Brewster DC, et al. Safety and efficacy of reoperative carotid endarterectomy: a 14-year experience. J Vasc Surg 2005;41:942-9.

Cite this article as: Stilo F, Montelione N, Calandrelli R, Distefano M, Spinelli F, Di Lazzaro V, Pilato F. The management of carotid restenosis: a comprehensive review. Ann Transl Med 2020;8(19):1272. doi: 10.21037/atm-20-963
147. Arhuidese IJ, Nejim B, Chavali S, et al. Endarterectomy versus stenting in patients with prior ipsilateral carotid artery stenting. J Vasc Surg 2017;65:1418-28. 